Geograficando, vol. 13, n. ${ }^{\circ}$ 1, e018, junio 2017. ISSN 2346-898X

Universidad Nacional de La Plata.

Facultad de Humanidades y Ciencias de la Educación.

Departamento de Geografía

\title{
Disputas en y por el territorio. El caso del macizo del deseado
}

\author{
Disputes and the territory. The case of Deseado massif
}

\author{
Silvia Valiente
}

Conicet CIT Santa Cruz/Universidad Nacional de la Patagonia Austral, Argentina | scvaliente@gmail.com

\section{PALABRAS CLAVE}

Mentalidad rentística

Trampa de la abundancia

Territorio

Disputas

Conflicto

\section{KEYWORDS}

Rentier mentality

Trap of abundance

Territory

Disputes

Conflict

\section{RESUMEN}

Este artículo examina algunos de los problemas que se desatan en el área del macizo del Deseado, centro-norte de la provincia de Santa Cruz, en la Patagonia austral argentina, un espacio donde se desarrolla de manera casi exclusiva la mega-minería metalífera como única actividad posible. En este contexto analizaremos las disputas que se desatan en y porel territorio producto de esta actividad, en un contexto donde la multiplicidad de sujetos que intervienen en el espacio complejizan los conflictos. En este escenario, la concepción de territorio propuesta por Bernardo Mançano Fernandes, apoyada en una perspectiva crítica, nos permite desarticular la trama del conflicto bajo una metodología cualitativa apoyada en fuentes secundarias. A nivel de resultados, este artículo expone el funcionamiento de la mentalidad rentística, la violencia y la trampa de la abundancia en regiones de vocación extractiva.

\section{ABSTRACT}

This article examines some of the problems presented in the area of the Deseado Massif, in the north-centre of the province of Santa Cruz, Argentina's southern Patagonia, a space in which the metalliferous mega-mining develops, almost exclusively, as the only possible activity. In this context, we will analyze the disputes that untie "in and for" the territory due to this activity, in a context where the multiplicity of people involved in this space make the conflicts more complex. In this scenario, the concept of territory proposed by Bernardo Mançano Fernándes, supported by a critical perspective, allows us to disrupt the plot of the conflict, under a qualitative methodology based on secondary sources. Regarding the results, this article describes the operation of the rentier mentality, the violence and the trap of abundance in regions with extractive vocation. 


\section{Introducción}

Este artículo aborda una parte de la dinámica geopolítica ligada a la reprimarización y recolonización de territorios ricos en recursos mineros ligados a la explotación metalífera en la Patagonia Austral argentina, y en la Provincia de Santa Cruz en particular. Se trabajará la dimensión espacial en términos de totalidad, multidimensional, multiescalaridad y complementariedad, cualidades y propiedades que reconoce en el territorio Mançano Fernandes.

A efectos de mantener la visión global de las dinámicas geopolíticas y sus correspondencias en espacios regionales, centraremos el análisis en un espacio donde se despliegan las actividades extractivas mineras, esto es, el Oeste y Centro-Norte de Santa Cruz, es decir, el área conocida como el macizo del Deseado.

Desde la década del noventa América Latina es la principal región del mundo hacia donde se dirige la explotación minera. Elites locales y sectores hegemónicos bajo la palabra desarrollo alientan el mito de la vocación minera (Villamar, 2011, p. 186).

En el área de estudio, el proceso mencionado viene desplegándose en las dos últimas décadas, y en especial en la primera del presente siglo, de una acelerada disputa por el control y acceso a recursos naturales cada vez más escasos. Esto refleja la presión que la economía ejerce sobre la naturaleza y el medio ambiente, en el marco del denominado modelo neoextractivo, de mercantilización y conversión de la naturaleza en activo financiero.

\section{Presentación del caso}

A diferencia de lo que ocurre en otras regiones de Latinoamérica, donde espacios de estas características están atravesados por el conflicto armado y el desplazamiento forzado, en este caso la población no asiste a estas conflictividades, pero sí a otras, como el no tener un fuerte arraigo al territorio no sólo por la escasa ocupación, sino por la alta movilidad de población que existe. Se trata de espacios poblados a partir de diferentes oleadas colonizadoras provenientes de distintas regiones del país y países limítrofes, en especial Chile, que se asentaron y dieron origen a los actuales núcleos poblacionales, muchos de los cuales tenían existencia en períodos prehispánicos con población mapuche.

Caracterizan entonces a este espacio la alta movilidad de población relacionada con la alta rotación de mano de obra, siendo muy bajo el porcentaje de población del área del macizo del Deseado empleada en la actividad minera metalífera. A su vez, por tratarse de una actividad tipo enclave, tiene una dinámica diferente a la campesina o agrominera en lo que hace a la cantidad de personas movilizadas ante un reclamo, situación que también incide en la escasa visualización de los conflictos tanto a nivel regional como extraregional.

Nos encontramos con una gran diversidad de sujetos, que de manera individual o colectiva, y desde diferentes posiciones, llevan adelante sus reclamos. Podemos asociarlos en dos grupos. Por un lado, los trabajadores mineros directamente afectados por las empresas mineras; y por otro, los habitantes de las localidades próximas a los yacimientos. Este último grupo está representado por los vecinos organizados en asambleas no partidarias que viven en las ciudades y localidades próximas a los emprendimientos en el área del macizo del Deseado. El común denominador en todos ellos es la escasa visibilidad que tiene el conflicto. Sólo aparece en medios virtuales $\underline{1}$.

\section{Patagonia argentina y Santa Cruz, territorios con vocación extractivista}

La Patagonia desde mediados del Siglo XIX aparece como un espacio de ocupación para la puesta en valor de la riqueza de los bienes comunes naturales de su suelo, del subsuelo y del litoral. Desde entonces se establece una dependencia de los recursos naturales. 
La meseta central es la región geológica más extendida de la Patagonia, abarcando desde el centro de la Provincia de Santa Cruz hasta la línea Sur de la Provincia de Río Negro. En esta región se sitúan los mayores yacimientos de minerales metalíferos y uranio de la Argentina. La cantidad de proyectos mineros expresa la vocación extractiva, y esto guarda relación con el hecho de ser Santa Cruz una de las provincias con los más altos porcentajes de población del país nacida en otra provincia, evidenciando intensos procesos migratorios. Según el Censo Nacional de Población, Hogares y Viviendas 2010, el porcentaje de población nacida en otra provincia en la provincia de Santa Cruz es del 43,5 \% (p. 107); apareciendo entre 2005 y 2010 como una de las provincias de mayor atracción a inmigrantes de acuerdo al Censo Nacional de Población, Hogares y Viviendas 2010.

\section{Macizo del Deseado: la única actividad posible es la minería}

La expresión contenida en el título está ligada a las ideas de desierto y a la narrativa del progreso en relación con el plano económico. Esta narrativa contiene una visión de desarrollo lineal y unidimensional, vastamente cuestionado desde las perspectivas críticas a partir de la segunda mitad del siglo XX.

A mediados del siglo XX, las formulaciones del desarrollo ya eran casi indistinguibles de las del crecimiento económico y los dos términos se intercambiaban en más de una obra clave (por ejemplo, Lewis, 1976). Ese crecimiento seguiría una serie de etapas, planteadas por Rostow (1961), donde los rezagados debían inspirarse y repetir el ejemplo de las economías avanzadas. Para estos autores el tema central era el crecimiento económico y no la distribución, y desde ese tipo de posturas se cimentó la insis tencia en apelar a indicadores como el Producto Bruto Interno, convirtiéndolo en una meta en sí mismo. De esta manera, se consolida a mediados del siglo XX una visión del desarrollo como un proceso de evolución lineal, esencialmente económico, mediado por la apropiación de recursos naturales, guiado por diferentes versiones de eficiencia y rentabilidad económica, y orientado a emular el estilo de vida occidental (Bustelo, 1998; Unceta, 2009) (autores citados por Gudynas en Lang y Mokrani, 2011, p. 23, citas en el original).

Este espacio visto como desierto, vacío, en el que sólo cabe el desarrollo de la minería por la improductividad de sus tierras, puede ser conceptualizado también como un espacio de reserva, como mencionamos anteriormente. Bajo estas concepciones de desarrollo y progreso se promueven y desarrollan actividades extractivas.

Asociado al extractivismo cabe mencionar la alta movilidad de población por el trabajo temporario, y el elevado índice de masculinidad (106 según el Censo Nacional de Población, Hogares y Viviendas 2010). En consecuencia, es mayormente masculina la mano de obra que se desplaza, sin generar arraigo en el territorio al no trasladarse con las familias. Sin embargo, pese a esa alta movilidad de población, la provincia está dentro de las que continúan atrayendo población, como ya se enunció.

"Una y otra vez resurge el mito de una región repleta de enormes riquezas - sin límites ambienta les- y que por lo tanto no pueden ser desperdiciadas, y deben ser aprovechadas con intensidad y eficiencia” (en Gudynas, en Lang y Mokrani, 2011, p. 37).

\section{La mentalidad rentística y la trampa de la abundancia}

La mentalidad rentística y la trampa de la abundancia genera disputas en y por el territorio, y son producto de lasdinámicas de acumulación del capital o, para ser más precisos, de la expansión del capitalismo a través de lo que Harvey define como:

acumulación por despojo [accumulation by disposession], comprendida por la destrucción de puestos de trabajo, la precariedad de las relaciones laborales y la destrucción de los territorios 
campesinos e indígenas. La acumulación por la expoliación significa una estado avanzado de las relaciones capitalistas que necesitan cada vez menos de recrear las relaciones no capitalistas. Es evidente que esta condición hace que el capital recree con menos intensidad trabajadores asalariados y territorios campesinos, aumentando el número de excluidos (Harvey, 2003, citado en MançanoFernandes, corchetes y cursiva en el original).

La cita de Harvey incorpora la noción de acumulación por desposesión; esta noción da cuenta de un proceso que ocurre en el espacio estudiado, aunque la destrucción de los territorios campesinos e indígenas haya ocurrido con anterioridad a la llegada de la megaminería. En este caso más bien es un proceso que data de la incorporación de estas tierras al proceso de organización del territorio nacional.

En esta acumulación del capital por desposesión, estos espacios se incorporan a las dinámicas globales de acumulación por desposesión por vías como la desregulación política y económica.

Como se anticipó, esta dinámica geopolítica de los recursos naturales parece estar guiada por una mentalidadrentística, cayendo en la trampa de la abundancia. Acosta (2009) reflexiona sobre cómo los países de Latinoamérica están atrapados por lo que denomina "la maldición de la abundancia":

Y son pobres porque son ricos en recursos naturales, en tanto han apostado prioritariamente por la extracción de esa riqueza natural para el mercado mundial, marginando otras formas de creación de valor, sustentadas más en el esfuerzo humano que en la generosidad de la naturaleza (p. 32, cursivas en el original).

En los territorios donde esto ocurre se genera una violencia desatada por las propias empresas extractivistas. Esto profundiza la débil y escasa institucionalidad, alienta la corrupción y deteriora el medio ambiente, como nos recuerda Acosta (2009). A esa mentalidad y trampa de la abundancia la examinaremos en un espacio concreto, como es el macizo del Deseado, espacio que vamos a conceptualizar como territorio de acuerdo al tratamiento de este concepto y categoría que hace Mançano Fernandes (2008 y sucesivos).

Este autor defiende una significación más amplia para el concepto de territorio, como multidimensional. Sintetizamos el tratamiento en la siguiente conceptualización:

La comprensión de cada tipo de territorio como una totalidad, con su multidimensionalidad y organizada en diferentes escalas, a partir de sus desiguales usos, nos posibilita entender el concepto de multiterritorialidad. Considerando que cada tipo de territorio tiene su territorialidad, los tipos de relaciones e interrelaciones nos muestran las múltiples territorialidades. Las multiterritorialidad une a todos los territorios a través dela multidimensionalidad y por medio de las escalas geográficas, que pueden ser representadas como camadas sobrepuestas en que una acción política se desdobla en varios niveles y escalas: local, regional, nacional $e$ internacional” (Mançano Fernandes, 2008)

\section{Las disputas en y por el territorio}

Iniciamos este apartado con la presentación de un cuadro de elaboración propia como modo de situar las conflictividades que en adelante presentaremos.

\section{Cuadro $N^{\circ}$ 1: Detalle de emprendimientos mineros metalíferos en el área del Macizo del Deseado}

\begin{tabular}{|l|l|l|l|}
\hline $\begin{array}{l}\text { Nombre del } \\
\text { emprendimiento }\end{array}$ & Localización & $\begin{array}{c}\text { Mineral y modo } \\
\text { de explotación }\end{array}$ & Empresa que lo explota \\
\hline $\begin{array}{l}\text { Manantial } \\
\text { EspejoOpera desde }\end{array}$ & $\begin{array}{l}\text { área de } 225 \mathrm{~km} 2, \text { a } 5 \mathrm{~km} \text { al } \\
\text { norte de la ruta, a } 50 \mathrm{Km}\end{array}$ & $\begin{array}{l}\text { oro, plata y otros } \\
\text { metales. Mina a }\end{array}$ & $\begin{array}{l}\text { Minera Triton es propietaria de la } \\
\text { canadiense Pan American Silver }\end{array}$ \\
\hline
\end{tabular}




\begin{tabular}{|c|c|c|c|}
\hline marzo de 2009 & $\begin{array}{l}\text { de Gob. Gregores y } 160 \text { al } \\
\text { oeste de Puerto San Julián }\end{array}$ & cielo abierto & $\begin{array}{l}\text { (Bill Gates es el dueño del el } \\
10 \% \text { y Silver Standard } \\
\text { Recsources. } \\
\text { Consume } 360 \text { mil litros de agua } \\
\text { por hora }\end{array}$ \\
\hline $\begin{array}{l}\text { San José-Huevos } \\
\text { Verdes. } \\
\text { opera desde } 2008\end{array}$ & $\begin{array}{l}\text { a } 50 \text { km de la localidad de } \\
\text { Perito Moreno, a } 7 \mathrm{~km} \text { al } \\
\text { sur de la confluencia de } \\
\text { los ríos Deseado y } \\
\text { Pinturas }\end{array}$ & $\begin{array}{l}\text { oro y plata. } \\
\text { Explotación } \\
\text { subterránea con } \\
\text { procesamiento de } \\
\text { mineral en la } \\
\text { provincia }\end{array}$ & $\begin{array}{l}\text { Minera Santa Cruz constituida } \\
\text { por Minera Andes (canadiense) y } \\
\text { Mauricio Hochschild (capitales } \\
\text { peruanos y americanos) }\end{array}$ \\
\hline $\begin{array}{l}\text { Cerro Vanguardia } \\
\text { opera desde } 1998\end{array}$ & $\begin{array}{l}\text { En el departamento } \\
\text { Magallanes y Deseado, a } \\
150 \text { km de Pto. San Julián } \\
\text { al noroeste }\end{array}$ & $\begin{array}{l}\text { oro y plata. } \\
\text { Explotación } \\
\text { subterránea y a } \\
\text { cielo abierto }\end{array}$ & $\begin{array}{l}\text { FOMICRUZ (7,5\%) en sociedad } \\
\text { con el consorcio británico Anglo } \\
\text { Gold Ashanti }(92,5 \%)\end{array}$ \\
\hline $\begin{array}{l}\text { Mina Marthaopera } \\
\text { desde } 2002\end{array}$ & $\begin{array}{l}\text { a } 69 \mathrm{~km} \text { al norte de } \\
\text { Gobernador Gregores }\end{array}$ & $\begin{array}{l}\text { oro y plata } \\
\text { hidrotermal } \\
\text { formado hace } 150 \\
\text { millones de años }\end{array}$ & $\begin{array}{l}\text { Desde } 2002 \text { explotada por Coeur } \\
\text { d'Alene (estadounidense) }\end{array}$ \\
\hline $\begin{array}{l}\text { Cerro Negroopera } \\
\text { desde } 2013\end{array}$ & $\begin{array}{l}\text { a } 70 \mathrm{~km} \text { de Perito Moreno } \\
\text { y a } 110 \mathrm{~km} \text { al sudoeste de } \\
\text { Las Heras }\end{array}$ & $\begin{array}{l}\text { oro y plata } \\
\text { subterráneo }\end{array}$ & GoldCorp (canadiense) \\
\hline $\begin{array}{l}\text { Minera Don } \\
\text { Nicolás } \\
\text { previsto su incio } \\
\text { para el tercer } \\
\text { trimestre de } 2016\end{array}$ & $\begin{array}{l}\text { a } 30 \text { km de Tres Cerros. Su } \\
\text { área de infuencia abarca } \\
\text { Fitz Roy y Jaramillo } \\
\text { Jaramillo y Fitz Roy } \\
\text { ubicadas a } 82 \text { y } 93 \\
\text { kilómetros al noreste del } \\
\text { sitio del proyecto }\end{array}$ & $\begin{array}{l}\text { oro y plata a cielo } \\
\text { abierto }\end{array}$ & $\begin{array}{l}\text { Minera IRL Ltd. adquiere } \\
\text { Hidefield Gold plc. ("Hidefield”), } \\
\text { propietaria de los derechos de } \\
\text { explotación de Don Nicolás y } \\
\text { otros proyectos en la zona del } \\
\text { Macizo del Deseado }\end{array}$ \\
\hline $\begin{array}{l}\text { Lomada de Leiva } \\
\text { opera desde } 2011\end{array}$ & $\begin{array}{l}\text { aproximadamente a } 40 \mathrm{~km} \\
\text { al SE de Perito Moreno }\end{array}$ & oro & Patagonia Gold y FOMICRUZ \\
\hline $\begin{array}{l}\text { proyecto Cap- } \\
\text { Oeste y Cap-Oeste } \\
\text { South-East } \\
\text { (COSE) }\end{array}$ & $\begin{array}{l}\text { aproximadamente a } 240 \\
\text { km al SE de Perito } \\
\text { Moreno }\end{array}$ & $\begin{array}{l}\text { oro a cielo abierto } \\
\text { y subterráneo }\end{array}$ & Patagonia Gold y FOMICRUZ \\
\hline $\begin{array}{l}\text { proyecto La } \\
\text { Manchuria }\end{array}$ & $\begin{array}{l}\text { aproximadamente a } 50 \mathrm{Km} \\
\text { al SE de Cap-Oeste }\end{array}$ & $\begin{array}{l}\text { oro. Explotación } \\
\text { subterránea }\end{array}$ & Patagonia Gold desde 2007 \\
\hline
\end{tabular}

\section{Fuente: Elaboración propia en base a la consulta de diferentes fuentes (actualizado a diciembre de 2016)}

Las disputas en y por el territorio se desatan en el espacio provincial, territorio entendido como totalidad, primer territorio contenedor del segundo y el tercero (en adelante se explicitará), contenedor también de múltiples territorialidades, siendo cada una de ellas multidimensional. Existen, al menos, dos proyectos político-estratégicos en disputa, en permanente conflictividad, producto de las políticas impartidas y de la diferente intencionalidad, atributos todos estos de los territorios que, por su naturaleza, son multiescalares, siendo todos ellos complementarios entre sí.

En consonancia con lo expresado hasta aquí, realizamos en adelante un ejercicio analítico para dar cuenta de estos atributos del territorio procurando superar la concepción reduccionista que analiza el territorio sólo como espacio de gobernanza, es decir, un espacio definido por las relaciones de poder ya sea desde el Estado, capital, instituciones, sujetos, donde el territorio es un instrumento de dominación y medio para la ejecución de políticas neoliberales. 


\section{El territorio es totalidad, por lo tanto es multiescalar}

En el análisis multiescalar reconoceremos las escalas territoriales y tipos de territorios materiales, que junto a los procesos geográficos primarios y procesos geográficos procedentes, permiten describir las conflictividades que desata la renta de los recursos naturales. A nivel de escalas territorial tenemos el primer territorio que estaría representado por la provincia de Santa Cruz, mientras que el segundo territorio, sería aquel donde predomina un tipo de propiedad, en este caso, la propiedad privada capitalista representada por el capital transnacional que explota el suelo y subsuelo de la provincia.

La procedencia de los capitales y la localización de sus oficinas nos articulan con otros territorios fuera del ámbito provincial. De acuerdo a esto, de las 16 empresas mineras que operan en la provincia, 6 tienen sus oficinas en Mendoza, 7 en CABA, 1 en Canadá y sólo 2 en el territorio provincial, en Puerto San Julián (fuente CAMICRUZ).

Incorporamos una imagen de la territorialización minera, es decir, de la expansión del territorio que se produce por el trabajo asalariado, originando paisajes de cierta homogeneidad en el segundo territorio. Así, el segundo territorio incluido en el primero se caracteriza por la explotación a gran escala y homogeneidad en el paisaje. En él, el trabajo es subordinado, controlado por los commodities, o la producción de materias primas que están destinadas a la exportación sin valor agregado.

Mientras que en el primer y segundo territorio son coincidentes las escalas territoriales con los tipos de territorios materiales, siguiendo la tipología de Mançano Fernandes (2008 y sucesivos), se añade a esta clasificación el tercer territorio material que sería, en nuestro estudio, el territorio controlado por los trabajadores, donde se disputan otras intencionalidades, otros intereses y, por lo tanto, se pretenden establecer otras relaciones de poder.

Podemos dar cuenta -siguiendo el pensamiento del autor referenciado- de este territorio que es transitorio, intermitente y no perenne como el espacio geográfico

Un ejemplo en nuestro estudio de ese tercer territorio alcanzando su expresión material se puede observar cuando los trabajadores mineros realizan paros y cortes de ruta ante sus reclamos no atendidos. La espacialización de esa acción se concretiza en el espacio, se transforma en un hecho consumado, y así estamos ante la existencia de ese tercer territorio.

La unidad minera "San José", operada por "Minera Santa Cruz", tiene paralizada las actividades desde el pasado viernes a las 22 horas, debido a que los trabajadores iniciaron una medida de fuerza ante el despido de 20 personas, anunciando asimismo que en los próximos días hará lo propio con otros 20 asalariados más, según indicó a este medio Rubén, vocero de los trabajadores autoconvocados” (Diario La Opinión Austral (12/7/2015).

En este ejemplo, la espacialización de la acción es precedida por la espacialidad de la misma, es decir, primero se concibe el significado de la acción, por eso es que la espacialización es subjetiva y, cuando se la concreta, se hace de esta intención un hecho objetivo.

Finalmente, a modo también de ejemplo de multiescalaridad, observamos la disputa en el área entre trabajadores mineros autoconvocados y actores ausentes en el territorio, como el magnate Bill Gates, dando cuenta de la multiplicidad de intereses y capitales que intervienen en la región. $\underline{2}$

\section{El territorio es totalidad, por lo tanto es multivocal}

Partiendo de la concepción de espacio como totalidad, identificaremos en este escenario de disputas y conflictos elementos que pueden ser analizados con mayor detalle desde alguna de las cualidades del 
territorio, aun reconociendo que todas ellas tienen componentes multiescalares, y que están en complementariedad. Y añadiremos un atributo no considerado por Mançano Fernandes que es el de multivocalidad (Valiente, 2013).

Voz y multivocalidad resultan criterios metodológicos, junto al de reflexividad, credibilidad y transferibilidad, propuestos por quienes adscriben al giro dialógico en la investigación social cualitativa (Lincoln, 2002; Denzin y Lincoln, 2003; Gergen y Gergen, 2003, citados en Sisto, 2008). Con anterioridad a tomar conocimiento del giro dialógico, ya había utilizado el concepto de multivocalidad a partir de lecturas antropológicas para referir a las múltiples voces que son constitutivas de la dimensión simbólica del espacio. En esa oportunidad refería a ella de la siguiente manera:

la multiplicidad de discursos o multivocalidades que se levantan en torno a la mega-minería, tanto las generadas desde el locus de enunciación colonialista, como las que reconocen un locus de enunciación crítico o decolonial. Este último, protagonizado por sujetos hegemonizados o subalternos -desde el punto de vista hegemónico-, produce discursos que entran en tensión con los generados por sujetos o sectores hegemónicos-neoliberales, en tanto que cuestionan las narrativas hegemónicas. (Valiente, 2013, pp. 6-7).

Retomo en este trabajo ese criterio para pensarlo como un atributo de la dimensión simbólica del territorio, en tanto los diferentes locus de enunciación son una dimensión también constitutiva del territorio. Cada voz refiere a una localización epistémica y geohistórica particular del sujeto; expresa la manera particular de nombrarnos, posicionarnos. En este sentido es que el territorio también se construye a partir de la multivocalidad.

A partir de esta cualidad la pregunta que surge es: ¿quiénes se disputan el área del macizo del Deseado? Por las multivocalidades reconocemos en el territorio la existencia de diferentes lugares de enunciación, de diferentes posiciones ocupadas por los sujetos vinculados a la minería en el sector, posicionamientos ligados a intencionalidades y diferentes proyectos político-estratégicos que motivan disputas que no sólo se resuelven entre el poseedor del capital y el poseedor de la fuerza de trabajo. La realidad evidencia ser más compleja, superando ese esquema dualista.

Por esta razón, se elaboró un cuadro que ilustra la diversidad de sujetos que se disputan el macizo del Deseado y que, desde diferentes posiciones de poder, muestran capacidad de resistir, mitigar o negociar, aún en un esquema de relaciones asimétricas de poder.

Cada sector tiene una relación particular con los recursos y disputan intereses diferentes. En este sentido es que merece atención la multiplicidad de actores interviniendo en el territorio. Encontramos:

\section{Cuadro N$^{\circ}$ 2: Multiplicidad de actores en el área del Macizo del Deseado}

\begin{tabular}{|l|l|l|}
\hline Trabajadores mineros & Nucleados en gremios & $\begin{array}{l}\text { AOMA-Asociación Obrera Minera Argentina } \\
\text { UOCRA-Unión Obrera de la Construcción de la } \\
\text { República Argentina } \\
\text { SITRADIC-Sindicato de Trabajadores de la Industria de } \\
\text { la Construcción y Afines } \\
\text { SIJEMIN-Sindicato del Personal Jerárquico Minero }\end{array}$ \\
\hline \multirow{2}{*}{ Habitantes del lugar } & $\begin{array}{l}\text { No agremiados } \\
\text { Trabajadores Mineros Autoconvocados }\end{array}$ \\
\cline { 2 - 3 } & $\begin{array}{l}\text { También el movimiento } \\
\text { Rio Santa Cruz sin } \\
\text { represas. }\end{array}$ & $\begin{array}{l}\text { - Vecinos Autoconvocados de } \mathbf{3} \text { : } \\
\text { Perito Moreno-Las Heras- Los Antiguos- Caleta Olivia- } \\
\text { Pico Truncado (poco activa)-Gobernador Gregores }\end{array}$ \\
\hline
\end{tabular}




\begin{tabular}{|c|c|c|}
\hline & $\begin{array}{l}\text { Algunas de estas son } \\
\text { temas de minería, otras } \\
\text { por petróleo, represas, } \\
\text { pero todas por la } \\
\text { cuestión del agua. }\end{array}$ & \multirow[t]{2}{*}{$\begin{array}{l}\text { (desactivada)-SOS x el agua (Caleta) } \\
\text { San Julián- Puerto Deseado (desactivadas las dos por } \\
\text { fallecimiento de sus referentes)- Río Gallegos } \\
\text { Red Ecosocialista en Santa Cruz (Caleta y Gallegos)- } \\
\text { El Chaltén (nueva)-El Calafate. }\end{array}$} \\
\hline & no Auto-convocados & \\
\hline \multirow[t]{2}{*}{ Empresas Mineras } & Sector empresarial & CAMICRUZ-Cámara Minera de Santa Cruz \\
\hline & Sector Pyme & $\begin{array}{l}\text { CAPROMISA-Cámara de Proveedores Mineros } \\
\text { Sociedad Anónima }\end{array}$ \\
\hline Estado Provincial & \multicolumn{2}{|c|}{ Ministerio de la Producción de la provincia } \\
\hline Estado Nacional & \multicolumn{2}{|c|}{ Ministerio de trabajo de Nación - Secretaría de Minería de Nación } \\
\hline
\end{tabular}

Fuente: Elaboración propia en base a la consulta de diferentes fuentes

Recurriendo nuevamente a la ejemplificación, resulta interesante observar cómo en el grupo de los trabajadores mineros se evidencian disputas que han dado lugar a una diversificación de nucleamientos, expresando no ser un colectivo homogéneo que reconozca o acuerde con los líderes sindicales. Esto quedó puesto de manifiesto con las detenciones ocurridas.

Los detenidos siguen exigiendo el compromiso del sindicato ante la situación que viven y desde AOMA han dicho que, por la calidad de las acciones de estos delegados, "no se pueden amparar en que fueron gremiales", lo que ha generado malestar entre quienes sostienen que Javier Castro (Secretario general) "se borró" y ha dejado en manos del Secretario Adjunto una tarea en la que el máximo dirigente debiera estar liderando (Agencia OPI Santa Cruz. "Están detenidos 3 delegados de AOMA y 7 operarios, por piquetes y reclamos, tras una denuncia de Minera Santa Cruz”, 2015)

La nota citada expresa la desconfianza de los trabajadores respecto a sus líderes sobre la negociación del conflicto. Las multivocalidades deben ser analizadas no sólo teniendo en cuenta el agrupamiento de los trabajadores, sino que deben considerarse otras variables como edad, lugar de procedencia, antigüedad en el trabajo en general, experticia, tiempo que llevan trabajando en la minera, nivel de instrucción alcanzado, sólo por citar algunos. La consideración de estas variables debe ser analizada en cada caso a modo de poder vincular la voz que se levanta o calla con la idea de trabajo, territorio, familia, estado y sociedad.

En este sentido es que la multivocalidad requiere de un análisis a partir de fuentes primarias como pueden ser las entrevistas, quedando limitado su tratamiento en este caso, cuyo análisis de apoya en fuentes secundarias exclusivamente.

De todos modos, podemos sintetizar diciendo que la emergencia de estas voces pone de manifiesto conflictividades relacionadas a diferentes dimensiones de la realidad, sobresaliendo la económica (mediante reclamos de mejora salarial) y ambiental (reclamo de mejores condiciones de seguridad e higiene), siendo dimensiones que afectan a todos los trabajadores mineros más allá de su filiación política o gremial.

\section{El territorio es totalidad, por lo tanto es conflictividad}

En este apartado nos enfocaremos en las múltiples conflictividades que se desatan en los territorios mineros. Una serie de acontecimientos se han sucedido en los territorios mineros, desde accidentes de trabajo hasta muertes dudosas, desde intoxicaciones masivas ocasionadas por el agua y la comida en el sitio de la mina hasta reclamos laborales. 
Desde el año 2011 se detectan sucesivas irregularidades liderando el ranking de reclamos la minera San JoséHuevos Verdes operada por Minera Santa Cruz. Se exponen solo algunos episodios:

- en 2009: se registraron 25 personas intoxicadas.

- en 2011: informaron de una extraña muerte ocurrida. La mujer fue encontrada muerta en la gamela del yacimiento a las 05:30hs. y, tanto desde la empresa como del gremio AOMA, se indicó que fue un suicidio por ingesta de barbitúricos.

- en 2012: un operario cayó por un agujero de ventilación que se estaba construyendo sin las debidas precauciones ni sistemas de seguridad y murió (“Minera Santa Cruz: sesenta operarios intoxicados”, 2013; y “Otro ocultamiento minero: al menos 25 trabajadores cianurados”, 2009).

- en 2013: más de 60 personas intoxicadas, 18fueron internadas en Perito Moreno ("Minera Santa Cruz: sesenta operarios intoxicados”, 2013)

- en 2015: Minera Santa Cruz durante 15 días transportó 3 camiones diarios de agua desde Perito Moreno (boca de abastecimiento de los Bomberos hacia la mina). Uno de los socios que posee la empresa que traslada el agua al interior de Minera Santa Cruz era el Secretario de Obras Públicas de la Municipalidad y la esposa trabajaba en la oficina de Relaciones Comunitarias de la minera Patagonia Gold (“Minera Santa Cruz: sesenta operarios intoxicados”, 2013)

- Esto demuestra la debilidad de las instituciones del Estado para hacer respetar las normas y fiscalizar las acciones gubernamentales.

En relación a la falta de seguridad e higiene, se registraron otros acontecimientos:

- deficientes condiciones del laboratorio de Minera Santa Cruz y deplorables condiciones de higiene y seguridad, sin ventilación ni medios adecuados para la protección del personal. Un mes después, la empresa modificó la situación y acondicionó las instalaciones para seguridad de la gente ("Minera Santa Cruz: sesenta operarios intoxicados”, 2013).

- aplicación de una multa a Minera Oro y plata SA en 2012 de la multinacional Goldcorp por falencias en seguridad e higiene. La multa ascendió a los \$20.405.700. Hubo reincidencia, motivo por el cual el 8/8/14 se le aplicó otra multa por el valor de \$22.356.00. Las irregularidades habían sido detectadas por 14 inspectores.

En relación a los reclamos salariales, reclamo de pago de feriados, premios, antigüedad, liquidación de bonos, horas extras y suplementos, se registraron numerosas protestas, algunas de las cuales terminaron en criminalización en 2015.

Las empresas aducen insuficiencia económica, volatilidad en los precios de las materias primas en el mercado mundial, en la balanza pagos y las cuentas fiscales. Todo esto se agravó en 2015 cuando se desata la caída de esos precios internacionales y la consecuente crisis de balanza de pagos. Finalmente, esta situación tuvo el siguiente desenlace:

12/7/15: intervino el Ministerio de Trabajo de Nación dictando la conciliación obligatoria y la reincorporación de los 40 despedidos. 
14/7/15: el Juez de Instrucción $N^{\circ} 1$ de Las Heras ordena reprimir, detener y procesar a 10 trabajadores que protagonizaban un corte de ruta.

En estos escenarios:

la violencia y la militarización de los territorios son la regla, forman parte inseparable del modelo; los muertos, los heridos y golpeados no son fruto de desbordes accidentales de mandos policiales o militares. Éste es el modo "normal" en que opera el extractivismo en la zona del noser (Zibechi, en Composto y Navarro, 2014, p. 77, comillas en el original).

En suma, los sucesivos conflictos distributivos por la renta son justificados desde las empresas por la pérdida de rentabilidad y fluctuaciones del mercado, situación que consolida el rentismo y el patrimonialismo.

Podemos analizar estos acontecimientos como parte de la reconfiguración de los territorios de destino por parte de las transnacionales, que en su modo de operar van subsumiendo todo tipo de relaciones, y lleva además a la pérdida de diversidad cultural y a la degradación de las condiciones ambientales.

\section{El territorio es totalidad, por lo tanto es complementariedad}

En este apartado abordaremos la dimensión jurídica o legal del conflicto que, como las restantes, es complementaria de la económica, social, cultural, y no menos conflictiva en el análisis de la dinámica territorial. En este caso, la dimensión jurídica abordada está en relación con las disputas que se desatan en torno a la cuestión del suelo y subsuelo, entendidos como propiedad inmobiliaria de la provincia.

El conflicto se desató cuando el 10 de julio de 2013 la legislatura de la provincia de Santa Cruz aprobó una ley que modifica el código fiscal de la provincia. Se trata de la Ley Provincial $\mathrm{N}^{\circ} 3318$ que establece un Impuesto al Derecho Real de Propiedad Inmobiliaria Minera, cuyo tributo anual sería del 1\% sobre el valor de las reservas que posee la mina. Este tributo anual sería aplicable a quienes tengan concesiones mineras sobre una mina situada en la provincia y cuenten con un Estudio de Factibilidad presentado (de las excepciones normadas se deduce que no necesariamente debe estar aprobado).

Este nuevo tributo impulsado por el gobernador Daniel Peralta afectaría a todas las compañías del sector asentadas en la provincia que reúnan las condiciones antedichas. La nueva ley permitirá al gobierno provincial aplicar sobre los concesionarios de proyectos mineros situados en Santa Cruz una alícuota del 1\% establecida sobre el valor de las reservas que posea la mina, conforme valuación determinada por la cotización Nacional o Internacional, según cual fuere más favorable a la provincia. El impuesto será liquidado mediante una declaración jurada anual que deberán presentar las empresas mineras, y el volumen de las reservas declarado no podrá ser menor al volumen consignado en el estudio de factibilidad y/o en los estados contables, más las variaciones emergentes de la explotación de la mina y la exploración llevada a cabo en la misma (Impuesto sobre el Derecho Real de la Concesión Minera en Santa Cruz, 2013). ${ }^{4}$

Como en los otros acontecimientos mencionados, este desató una serie de acciones:

El 22 de julio de 2013 las mineras y el secretario de Minería de Nación Mayoral se pronunciaron en contra argumentando que la aplicación de esta nueva ley es ilegal y peligroso porque "no incentiva la inversión” (“Opi Santa Cruz: mineras y Mayoral contra el impuestazo”, 2013).

La minera Goldcorp (que administra Cerro Negro) fue la más taxativa al respecto. Suspendió la campaña de perforación aludiendo que la baja en los precios internacionales había disminuido los ingresos de la empresa. La nota que se incorpora abajo, en parte cuestiona esta postura: la entrada en producción de Cerro Negro impulsó fuertemente las colocaciones de oro y plata. Las 
de oro avanzaron 105,2 por ciento medidas en toneladas, mientras que en dólares marcaron una suba de 52,5 por ciento interanual. Las exportaciones de plata, por su parte, subieron 14,1 por ciento en cantidades y 12,1 en moneda norteamericana.

(Los nuevos proyectos que impulsan las exportaciones, 2015).

El gobernador a la fecha, Daniel Peralta, expresa que las empresas están acostumbradas a llevarse todo y que la minería es una de las actividades más extractivas con la mano de obra más barata. Esta es una característica de las economías primario-exportadoras donde lo que se exporta es la naturaleza y los capitales reflejan un escaso interés por invertir en el mercado interno. Esto redunda en una limitada integración del sector exportador con la producción nacional. En relación a esto, casualmente Minera Santa Cruz es la que menos compra a los proveedores locales.

Minera Santa Cruz es la empresa que refleja la peor situación con las empresas locales. Está en el puesto $\mathrm{N}^{\circ} 1$ de las que menos compran en la localidad y en la Provincia de Santa Cruz. [Por otra parte, el Gerente Operativo sostuvo que] la situación habla por sí sola” [ya que de 24 empresas visitadas la mencionada operadora sólo compra a 2 y su relación con la comunidad en cuanto al desarrollo de empresas es muy mala ("Minera Santa Cruz es la empresa que menos compra en la Provincia”, 2016)

En general se trata de escenarios en los que, como explica Acosta, no hubo incentivos para desarrollar y diversificar la producción interna vinculándola a los procesos exportadores para transformar los recursos naturales en bienes de mayor valor agregado. "Esta situación es explicable por lo relativamente fácil que resulta obtener ventaja de la generosa naturaleza y de una mano de obra barata” (Acosta, 2009, p. 27).

El conflicto desarrollado en este apartado fue resuelto en la Corte Suprema de Justicia dos años más tarde, cuando ésta hizo lugar a la medida cautelar interpuesta por Minera Triton (que explota Manantial Espejo), considerando que se le provocaba un daño a la minera y exigiendo al estado provincial se abstenga de reclamar. Este sin duda constituyó el primer antecedente que inclina la balanza en favor del capital transnacional.

\section{Reflexiones finales}

Podríamos hacer una síntesis del caso estudiado diciendo que a la territorialización minera no le precedió la desterritorialización del campesinado u otros sujetos, ya que estos procesos se produjeron en tiempos pretéritos coincidentes con la organización del Estado nacional y la incorporación de estas tierras al territorio nacional mediante la Campaña del Desierto (del último decenio del siglo XIX), cuando se desplazó de sus tierras a la población mapuche. Mançano Fernandes (2008 y sucesivos) nos recuerda que siempre la territorialización del capital significa la desterritorialización del campesinado y viceversa.

En este caso, pudimos observar que dentro del proceso de territorialización del capital se dio la creación de nuevas territorialidades sobre grandes extensiones de tierra improductivas (desde el punto de vista hegemónico), escenario que justificó la apropiación por parte del Estado de esos territorios y su concesión minera. Sobre ese vacío representado por la estepa se produjo la apropiación del mismo mediante mecanismos de acumulación por desposesión, acentuando la condición periférica de la región bajo una mentalidad rentística, cayendo en la trampa de la abundancia. Así, estos territorios se integran como espacios periféricos al capital global como economías primario-exportadoras, situación que genera múltiples conflictividades y disputas en y por el territorio. 


\section{Notas}

1 Las problemáticas son tratadas por medios de comunicación que pertenecen casi exclusivamente a la escala local-regional (diario La Opinión Austral, prensa Libre on line, noalamina.com, OPI Santa Cruz y otros sitios virtuales), estando prácticamente ausentes en los medios de alcance nacional.

$\underline{2}$ "El dueño de Microsoft tiene un 10\% de una empresa que explota el yacimiento de plata, oro y otros metales "Manantial Espejo" en la Patagonia. La explotación será a cielo abierto y con el uso de cianuro. Esto generó el rechazo masivo de los vecinos de la zona que denuncian la contaminación de las aguas con cianuro" (Diario Crítica Digital, 29/01/09).

$\underline{3}$ Gentileza de Schweitzer, Alejandro.

4 Como resultado de esta compleja ecuación, las empresas no podrán especular con las variaciones del contexto declarando menos de lo establecido en los estudios de factibilidad

\section{Fuentes Consultadas}

Acosta, A. (2009). La maldición de la abundancia. Quito:Abya-Yala.

Censo Nacional de Población, Vivienda y Hogares 2010. Ciudad Autónoma de Buenos Aires: INDEC.

Composto, C. y Navarro, M. (2014). Claves de lectura para comprender el despojo y las luchas por los bienes comunes naturales en América Latina. En Composto, C. y Navarro, M.(comp.)Territorios en disputa (pp.3376) México: Tierra Ediciones. $1^{\circ}$ Edición.

Gudynas, E. (2011) Debates sobre el desarrollo y sus alternativas en América Latina: una breve guía heterodoxa. En Lang, M. y Dunia M. (comp) Más allá del desarrollo. (pp. 21-54) Quito: Fundación Rosa Luxemburg/Abya Yala

Mançano Fernandes, B. (2008).Sobre la tipología de los territorios. Recuperado de http//web.ua.es-engiecryal-documentos-documentos839-docs-

Mançano Fernandes, B. (2008). La ocupación como una forma de acceso a la tierra en Brasil: una contribución teórica y metodológica. En Moyo, S. y Yeros. P. (cooed.), Recuperando la tierra. El resurgimiento de movimientos rurales en África, Asia y América Latina. Ciudad Autónoma de Buenos Aires: CLACSO. Recuperado de http://bibliotecavirtual.clacso.org.ar/ar/libros/sursur/moyo/15Fernandes.pdf (consultado en marzo de 2016).

Mançano Fernandes, B. (2009). Territorio, teoría y política. Recuperado de http://www.modulosocioterritorial.files.wordpress.com2009081bernardo(consultado en marzo de 2016).

Mançano Fernandes, B. (s/f). Movimientos socioterritoriales y movimientos socioespaciales Contribución teórica para una lectura geográfica de los movimientos sociales. Recuperado de http://www.ua.es-engiecryal-documentos-documentos839-docs-bmfunesp-5 (consultado en marzo de 2016).

Sisto, V. (2008) La investigación como una aventura de producción dialógica: La relación con el otro y los criterios de validación en la metodología cualitativa contemporánea. Psicoperspectivas, VII, 114-136. Recuperado de http://www.psicoperspectivas.cl (consultado en julio de 2012).

Valiente, S. (2013). Santa María y Bajo de la Alumbrera: multivocalidades, multiterritorialidades y representaciones en tensión. En Cardinalis,1. Córdoba: Departamento de Geografía de la Facultad de

Filosofía y Humanidades, Universidad Nacional de Córdoba. Recuperado 
de http://www.publicaciones.ffyh.unc.edu.ar/index.php/geo

Villamar, A. (2011) Megaproyectos mineros en el área de Mesoamérica, elementos de una geoestratégica transnacional hemisférica. En Sandoval Palacios, J.; Álvarez de Flores, R. y Fernández Moreno, S. (coord.) Planes geoestratégicos, desplazamientos y migraciones forzadas en el área del proyecto de desarrollo e integración de Mesoamérica (pp. 182-190) Medellín: Universidad de Antioquia. Primera Edición

Zibechi, R. (2014).El estado de excepción como paradigma político del extractivismo.En Composto, C. y Navarro, M. (comp.), Territorios en disputa (pp.76-89) México: Tierra Ediciones. $1^{\circ}$ Edición.

\section{Sitios en internet}

Diario Crítica Digital (29/01/09) La mina de Bill Gates ya extrae oro y plata del árido suelo de Santa Cruz [consulta: 22 de marzo de 2016].

Minera Santa Cruz es la empresa que menos compra en la provincia, recuperado de http://capromisa.animusargentina.com/leer/noticia/minera-santa-cruz-es-la-empresa-que-menos-compra-enla-provincia/55 [consulta: 18 de marzo de 2016].

Página OAMA. recuperado de http://aomasantacruz.com/2016/01/aoma-protesta-donde-tiene-que-protestar/ [consulta: 22 de marzo de 2016].

Sitio El Inversor On Line (10/7/2013) Impuesto sobre el Derecho Real de la Concesión Minera en Santa Cruz, recuperado de http://elinversoronline.com/2013/07/impuesto-sobre-el-derecho-real-de-la-concesionminera-en-santa-cruz/ [consulta: 20 de marzo de 2016].

Sitio Miningpress (22/07/2013) Mineras y Mayoral contra el impuestazo, recuperado de http://www.miningpress.com.ar/nota/80467/opi-santa-cruz-mineras-y-mayoral-contra-el-impuestazo [consulta: 22 de marzo de 2016].

Agencia OPI Santa Cruz (8/8/2014) Millonaria multa a una minera de Santa Cruz por fallas en seguridad e higiene, recuperada de http://www.rionegro.com.ar/diario/millonaria-multa-a-una-minera-de-santa-cruz-porfallas-en-seguridad-e-higiene-3685567-10948-nota.aspx. Fuente: Opisantacruz.com.ar [consulta: 11 de marzo de 2016].

Agencia OPI Santa Cruz (23/02/09) Otro ocultamiento minero: al menos 25 trabajadores cianurados, Santa Cruz, Argentina, recuperado de http://www.conflictosmineros.net/noticias/2-argentina/4625-4625. Agencia OPI Santa Cruz [consulta: 21 de marzo de 2016].

Sitio Anred (7/2/2013) Minera Santa Cruz: sesenta operarios intoxicados”, recuperado de http://www.anred.org/spip.php?article5810 [consulta: 22 de marzo de 2016].

Sitio Noalamina (11/6/2015) Minera acarrea agua desde la ciudad de Perito Moreno hacia su yacimiento de oro, recuperado de http://www.noalamina.org/mineria-argentina/santa-cruz/item/14223-minera-acarrea-aguadesde-la-ciudad-de-perito-moreno-hacia-su-yacimiento-de-oro [consulta: 25 de marzo de 2016].

Agencia OPI Santa Cruz (5/6/2015) 20 despidos en Minera Santa Cruz y 20 más en próximos días, sepultan de realidade las palabras del diputado Leonardo Álvarez, recuperado de http://opisantacruz.com.ar/home/2015/06/05/20-despidos-en-minera-santa-cruz-y-20-mas-en-proximos-diassepultan-de-realidad-las-palabras-del-diputado-leonardo-alvarez/28680 [consulta: 22 de marzo de 2016].

Diario La Opinión Austral (12/7/2015) Se agravó el conflicto entre Minera Santa Cruz y AOMA, recuperado de http://www.laopinionaustral.com.ar/diario.asp?Modo=Noticia\&NId=62288 [consulta: 25 de marzo de 
2016].

Agencia OPI Santa Cruz (14/7/2015) Están detenidos 3 delegados de AOMA y 7 operarios, por piquetes y reclamos, tras una denuncia de Minera Santa Cruz, recuperado de http://opisantacruz.com.ar/home/2015/07/14/estan-detenidos-3-delegados-de-aoma-y-7-operarios-porpiquetes-y-reclamos-tras-una-denuncia-de-minera-santa-cruz/29596 [consulta: 18 de marzo de 2016].

Diario Nuevo Día - Santa Cruz (15/7/2015) SITRAIC reclama libertad a los mineros y "basta de criminalización de la protesta" Minera Santa Cruz: SITRAIC reclama libertad a los mineros. [consulta: 22 de marzo de 2016].

Diario Tiempo Sur (15/7/2015) Rechazo a decisión de juez de detener mineros y dictarles prisión preventiva. [consulta: 22 de marzo de 2016].

Diario Tiempo Sur (15/7/2015) Minera Santa Cruz: detuvieron 3 delegados de AOMA y 7 operarios por piquetes y reclamos [consulta: 20 de marzo de 2016].

Diario Tiempo Sur (15/7/2015) Estamos haciendo lo posible para que salgan los trabajadores detenidos. [consulta: 22 de marzo de 2016].

Un pedido de intervención en el conflicto de Minera Santa Cruz, recuperado de http://www.laopinionaustral.com.ar/diario.asp?Modo=Noticia\&NId=6331 [consulta: 22 de marzo de 2016].

Diario La Opinión Austral (5/8/2015) AOMA: “sin seguridad no hay minería, recuperado de http://www.laopinionaustral.com.ar/diario.asp?Modo=Noticia\&NId=69862\&texto=\&A=2016\&M=1\&D=7 [consulta: 17 de marzo de 2016].

Diario La Opinión Austral (10/2/2016)Alvarez: "buscan instalar el conflicto social en Santa Cruz, recuperado de http://www.laopinionaustral.com.ar/diario.asp?odo=Noticia\&NId=71195\&texto=\&A=2016\&M=2\&D=10 [consulta: 22 de marzo de 2016].

- Agencia OPI Santa Cruz (6/7/2015) La Corte Suprema de Justicia falló a favor de Minera Triton y no permite a la província cobrarle impuesto Inmobiliario, recuperado de http://opisantacruz.com.ar/home/2015/07/06/la-corte-suprema-de-justicia-fallo-a-favor-de-minera-triton-yno-permite-a-la-provincia-cobrarle-impuesto-inmobiliario/29446 [consulta: 25 de marzo de 2016]. 